\title{
THE HOMO STIMULUS: THE CREATION OF A NEW HUMAN BEING - SHAPED BY THE STIMULUS SOCIETY AND BEHAVIORAL CAPITALISM - IN THE AGE OF COLLECTIVE INDIVIDUALISM.
}

\author{
Andreas Herteux
}

Erich von Werner Society - Germany

DOI: 10.46609/IJSSER.2020.v05i01.013 URL: https://doi.org/10.46609/IJSSER.2020.v05i01.013

- The confrontation of the population with artificially generated stimuli has increased massively in recent decades.

- Technological development now makes it possible to stimulate all areas of personal life

- The population became accustomsed to fast and short stimuli

- These are not only passively consumed, but also actively demanded and shaped.

- The modern stimulus society ${ }^{\mathbf{1}}$ has come into being

- This stimulus society has therefore conditioned a new human being: the homo stimulus.

- The stimulus society, in combination with behavioral capitalism, has ushered in the age of collective individualism.

At the beginning there should be a thesis: The world is changing at a rapid pace. But it is not only she who is breaking new ground, but also man himself. The homo stimulus was born, the stimulus man, whose share of the total population is constantly increasing and which will make up a majority in future generations.

An evolutionary development? An adjustment? A product of external influence? It depends on the point of view, but the following pages do not want to repeat the basics of the social sciences,

\footnotetext{
${ }^{1}$ It is always a question of how terms are translated. In the contrary case it is about the translation of the term "Reizgesellschaft" into English. Here several variants would have been conceivable, however in the end "stimulus society" was chosen. But why not "irritable society", "irritant society" or "stimulated society"? All this would have been possible, but it would distort the view, because it is not about a society that is stimulated, but also stimulates itself. For this reason it ultimately became "stimulus society". This formulation is more neutral and leaves the action open. Of course, this decision does not have to be followed.
} 


\section{International Journal of Social Science and Economic Research}

ISSN: $2455-8834$

Volume: 05, Issue: 01 "January 2020"

for this there are undoubtedly better attempts, but rather a development of conditioning for fastfrequented stimuli and their end product, the homo stimulus, consider and put these to discussion. It remains a thesis that is intended to serve the understanding of a new reality. The first is already necessary because the changes are obvious and therefore absolutely require new explanatory approaches.

The new human being, shaped by the stimulus society, made the success of behavioral capitalism $^{2}$ possible in the first place and represents an essential characteristic of the age of collective individualism. The world of the present and future would be unthinkable without the homo stimulus and therefore it is necessary to name this conditioning, which has never happened before in such a framework, and thus to create a generally understandable basis for understanding and discussion. It is the continuation of the eternal task that each new age imposes on us and at the same time harbours the danger of falling back on obsolete models of the past to explain the present. But it may also be the eternally same flow of humanity into which we enter, but as Heraclitus remarked thousands of years ago, it never carries the same waters.

However, before the new human being is to receive a deeper dedication, it seems advisable to first explain what this scripture understands by a stimulus, i.e. a so-called stimulus and the stimulus society from which the homo stimulus has grown. However, this should not lead to a distance from the scientific standard, at best a shortening.

\section{A stimulus triggers or changes a behavior by acting on a sensory organ. The excitation is followed by a reaction. This reaction can be influenced by past stimuli.}

So far at least the psychological definition as it can be found in almost all accepted works. The distinction between reactive (first stimulus, because reaction) and operant behaviour (first reaction, then stimulus) should only be of limited interest at the moment, because these points are simply of secondary importance for thesis and objective.

The basic principle is not difficult to understand and should also be briefly presented here for people who are only concerned with such topics in the minor matter:

The bright sunlight closes the eyes. A pleasant smell of food reminds not only of one's own hunger, but also of when the dish was last eaten. The human being is therefore constantly exposed to stimuli, which he perceives almost continuously and in a variety of ways, consciously and unconsciously. This view is simplistic, but nevertheless it can be said that a world without stimuli would be difficult to imagine.

\footnotetext{
${ }^{2}$ Cf. First Foundations of Behavioural Capitalism: Inventory of a New Variety of Capitalism, by Andreas Herteux, published by Erich von Werner Verlag, 2019, ISBN 978-3981900651, DOI 10.5281/zenodo.3469587 
But doesn't he live with it already from the beginning of times in a stimulating society? One could be subject to this judgement if one were to define the concept very broadly, and yet the definition of the modern stimulus society, as it understands this script, is far more specific, more limited and ultimately the term for a historical development that refers to a very specific temporal sequence.

\section{An stimulus society is generally understood to be an association of individuals who are}

exposed to stimuli which influence a strong frequency, which are usually artificially generated, and who find it difficult or impossible to resist these stimuli, or in some cases do not wish to resist them.

Therefore, there is a demarcation between classical stimuli and a highly frequented stimulus, which has its origin in the commercialized and/or politicized technological development, the progress of which intensifies and thus, together with behavioral capitalism, ${ }^{3}$ has ushered in the age of collective individualism in the Western world. ${ }^{4}$

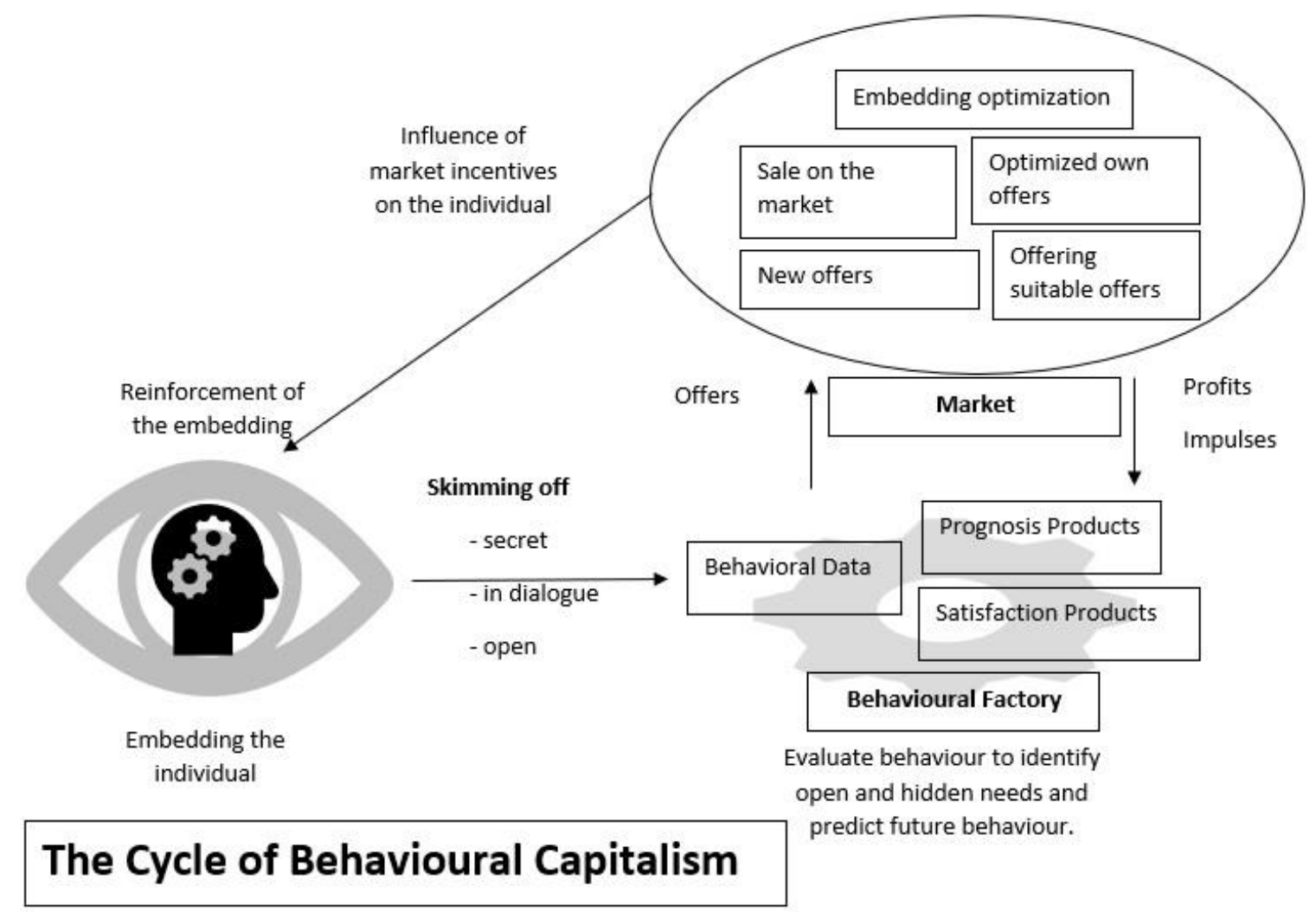

Alle Rechte Erich von Werner Society 2019

\footnotetext{
${ }^{3}$ First Foundations of Behavioural Capitalism: Inventory of a New Variety of Capitalism, by Andreas Herteux, published by Erich von Werner Verlag, 2019, ISBN 978-3981900651, DOI 10.5281/zenodo.3469587

${ }^{4}$ Herteux, Andreas, The Age of Collective Individualism, e.g. https://www.freitag.de/autoren/aherteux
} 


\section{International Journal of Social Science and Economic Research}

ISSN: $2455-8834$

Volume: 05, Issue: 01 "January 2020"

This may sound abstract at the moment, but will be made clear later at the concrete development. Up to this point, however, the definition itself must be deepened.

\section{A prerequisite for the establishment of a stimulus society is the possibility of confronting the individual with the stimuli with great frequency.}

This prerequisite of the stimulus society is elementary, because at this point there is a clear demarcation to a general understanding of stimulation. The development of the stimulus society and thus ultimately of homines stimuli cannot be separated from the technological development, which in turn is closely linked to scientific findings and their use by politics (e.g. political marketing), society (e.g. development of social milieus) and above all the economy (e.g. development towards a consumer society and later behavioural capitalism). Rather, it is an inseparable interaction of forces, which, however, will still experience a clear representation.

\section{The stimulation in modern times is mostly done by short, fast and repetitive stimuli.}

This statement is an important one, because here a gradual change in the type of perception has been initiated, because the stimuli have a different nature than a few decades ago.

Many of the social media, means of communication or services very often used today ${ }^{5}$ offer fast information and entertainment, which do not attach importance to a longer-term occupation with them and were also never thought in such a way. ${ }^{6}$ It also remains irrelevant whether first the stimuli were present, or the desire for them. The question is not goal-oriented, because it was rather a dancing together, which became faster and faster. A mutual increase and challenge. It's supposed to count the result.

The brain is therefore conditioned in a certain way that may not be comprehensible to people who have not yet exposed themselves to this process from a young age, and yet the result cannot be overlooked by them from their own empiricism: be it on the means of communication (e.g. smartphone) of third parties or simply on the faster cuts of films and their comparison with older screen products. Whether a dependency ratio of short and fast stimuli can arise here is not to be discussed at this point. Later, corresponding studies will be linked that suggest this. For the moment, however, another central feature of the modern stimulus society is to be pointed out:

\section{The stimulus exposure is often voluntary}

\footnotetext{
${ }^{5}$ Just think of services like WhatApp, Snapchat, Youtube or Instagram.

${ }^{6}$ For example, short entertaining and informative videos, the presentation of large numbers of posts, in which the brain filters out interesting ones in fractions of a second, and the familiarization with the constant beeping of the smartphone. This implements a habituation process that manifests itself in a change in perception.
} 


\section{International Journal of Social Science and Economic Research}

ISSN: $2455-8834$

Volume: 05, Issue: 01 "January 2020"

While commercial stimuli (e.g. TV advertising) were often perceived as annoying in earlier days, today's debate with them is not only based on free will, but is even actively demanded. It is therefore too brief to speak of a "bombardment" because it is a process in which both sides play the role of sender and receiver. ${ }^{7}$

So the smartphone is a constant companion and the constant checking of posts, messages and notifications for some people almost secondly standard. The ${ }^{8}$ boundary between commercial and private stimuli is becoming increasingly blurred, opening the door to man's most intimate sphere, which has generally remained closed to earlier "stimulus methods". This line is now open. The distinction between internal/external motivation or between requested and received stimuli is becoming increasingly insignificant and difficult to distinguish.

A weighty difference that at some point ${ }^{9}$ gave rise to a new variety of capitalism, behavioral capitalism, whose model explains the mechanisms described in depth. But we should not go that far at this point, we stick to the usually artificially set stimuli, which originally serve a purpose. But this already suggested the use of the word "conditioning", in which chains of associations such as "behaviorism", "framing" or "priming" often emerge, and yet these chains would not be sufficient to describe the development of a new time. But the truth remains the same:

\section{The aim of artificial stimulation is to influence behaviour}

This knowledge is not new and certainly not new. It does not matter whether the perceiver is to be moved to a purchase, to a click, only to a look or to a modification of behaviour with the stimulus. And the same goes for you, as always:

\section{Not every milieu or individual reacts equally strongly to the same stimulus. However, no one is completely immune.}

It is understandable that not every milieu or individual reacts in the same way to the same stimulus, since they have different views, values and interests. This, too, is not a new finding; otherwise, for example, extensive segmentation in marketing would not be necessary. And yet the difference has to be pointed out again:

This writing is not about whether certain stimuli achieve their goal, but about conditioning and a shift in perception in the direction of short, highly frequented stimuli, or even being driven

\footnotetext{
${ }^{7}$ It does not matter whether this interaction is only carried out by humans or also by a machine/CI. Reference should be made here to absorption in the sense of the behavioural capitalism model.

${ }^{8}$ Of course we are exaggerating a little at this point, but the human-smartphone symbiosis is also a perceptible reality.

${ }^{9}$ First Foundations of Behavioral Capitalism: A New Variety of Capitalism Gains Power and Influence, Andreas Herteux, Erich von Werner Verlag, 2019, ISBN 978-3981900675, DOI 10.5281/zenodo.3469568
} 
International Journal of Social Science and Economic Research

ISSN: $2455-8834$

Volume: 05, Issue: 01 "January 2020"

forward by the homines stimuli. It's about the global consequences. It is about a world in which the sensory organs are confronted with vast amounts of stimuli and at a breathtaking speed. It is a reality in which there is already a considerable habituation process. It is about how the human being changes in his behaviour and in his contemplation of his own reality. Change the methodology and structure, not the individual appeal. The human being is conditioned and newly shaped.

\section{Many stimuli completely miss their target and/or perish in the sea of stimuli. Nevertheless,} they influence the way in which those permanently exposed to the stimuli perceive them.

It would therefore be a misinterpretation to associate the terms "stimulus society" and "homo stimulus" exclusively with more clever manipulation, whether for economic or political purposes. There would be a frightening carelessness, because in fact a shift in perception, a new incarnation, is at the centre, because stimulation may originally have had a commercial-political background, but today the former stimulus recipients are often, if not as a rule, also transmitters and enter into a stimulus dialogue, just think of those millions who seek distraction in Instagram, Youtube and the like.

This process seems to have already been completed in parts of the milieus, in others it is still in an initial stage, beyond which it may not go in some cases.

\section{In the long term, exposure to stimuli changes the way of thinking, perception, decision- making processes and communication of the stimulus recipients.}

The homo stimulus is created, the stimulus man.

These changes in perception have long-term consequences for the relationship of consciousness with its environment. At least numerous studies suggest this ${ }^{10}$. The theory of the stimulus society and the homo stimulus only draws the necessary conclusions for a new era.

${ }^{10}$ These are not speculations. In the meantime, there are strong indications that support the thesis:

- The attention span decreases with the sensory overload (cf. study by the Max Planck Institute: https://www.nature.com/articles/s41467-019-09311-w).

Perhaps it would make more sense to note, however, that it does not sink, but is conditioned to short and fast stimuli.

- According to observations, parts of the brain become measurably more active and sensitive during intensive smartphone use for thumb stimuli. A positive effect. In general, manual dexterity outside the usual professions is likely to have increased. But that is again only one thesis.

- Some studies suggest that intensive use of digital media, which are responsible for a variety of stimuli, increases anxiety, attention disorders, lack of exercise or depression, or creates perception problems. An example from Great Britain: 
International Journal of Social Science and Economic Research

ISSN: $2455-8834$

Volume: 05, Issue: 01 "January 2020"

The human being is reprogrammed in parts. By clever manipulators? No, even by himself, because he accepts the modern stimulus society in many, although not all, cases and makes his contribution.

It has already been noticed that the depth of conditioning varies from environment to environment and from individual to individual. Therefore, only a part of mankind has already undergone the "evolutionary" development into a homo stimulus. Future generations, however, will grow up in an age of collective individualism and thus be confronted with stimuli practically from birth. If they want to enjoy the advantages of a high-tech world of conditioning, they will hardly be able to escape it.

With these explanations we want to conclude the attempt of the demarcation and the definition of the stimulus society and ask immediately for excuse for the abstraction. As a result, the study of the history of the stimulus society will now progress.

\section{Development of the stimulus society}

The stimulus society did not come out of the obscure nothingness, but has a long history of origins. ${ }^{11}$ This will now be examined in more detail in the following.

(https://www.rsph.org.uk/uploads/assets/uploaded/62be270a-a55f-4719-ad668c2ec7a74c2a.pdf)

- Some studies claim to have shown a link between ADHD and digital consumption: https://jamanetwork.com/journals/jama/article-abstract/2687861

The list can be continued for a long time, but there is no question that the studies are more in the direction of proving a damaging effect of the stimuli than a beneficial one. It is then a pleasure to present preliminary theses, such as that visual media would shrink the cerebral cortex of children, as a fact. However, the studies only allow this conclusion to a limited extent and further causes are open. (Examples: https://onlinelibrary.wiley.com/doi/full/10.1111/adb.12570 or alternatively

https://journals.plos.org/plosone/article?id=10.1371/journal.pone.0195549) As this is a new phenomenon, there are of course no diverse interpretable long-term studies available and even then one will face the problem of comparison groups in the future.

The only thing that remains important for us is that the intensified sensory overload has consequences. The human being is reprogrammed and conditioned by the stimuli. Whether this is to be evaluated positively or negatively should not interest us at the moment, because in a networked world with manifold influencing factors this is not as easy to decide as some would like it to be. Perhaps the world of collective individualism needs far less of the old, but all the more of the stimulus people? Nevertheless, it should be noted that this is a two-way process, both on the part of the sender and on the part of the recipient, of adaptation and habituation.

${ }^{11}$ The fact that different factors have to interact with each other has been pointed out more than once. 


\section{International Journal of Social Science and Economic Research}

ISSN: $2455-8834$

Volume: 05, Issue: 01 "January 2020"

By the 19th century at the latest, the conviction that the spirit and soul of man are dispensable and that only the right switches need to be operated in order to trigger a definable reaction gained more and more influence in the scientific world. Driven by the industrial revolution, a new image of man slowly developed: the individual is nothing more than a complex biological machine. The individual components only had to be understood in order to ultimately become the Creator themselves. Of course, not everyone shared these views, especially the clergy, of course, and yet they prevail in the end. Man was ultimately reduced more and more to the earthly, the visible. Science versus myth and religion. Explainable matter versus psychic soul. Pure empire against inner psychological processes. If we want to look at it from the philosophical point of view, we see here materialism and its variations naturalism and realism in pure form. ${ }^{12}$ Freed from clerical shackles, it was now a matter of solving the mystery of man and the result was a high of science, pseudoscience and popular literature in this and related areas. ${ }^{13}$ Old questions of philosophy could be reformulated and empirically researched. What is it that makes man so special? What is human behavior? Is it controllable? Subsequently, these questions were approached from different perspectives, which are separated here for illustrative purposes only, although separatism should make little sense here:

- Science (mass psychology, ${ }^{14}$ individual psychology, ${ }^{15}$ biology, ${ }^{16}$ law, ${ }^{17}$ etc.)

${ }^{12}$ Significantly, the new belief in technology parallel to science also plays a major role in contemporary literature and contributed to the dissemination of the new ideas to the public. Although many of these works ultimately represented nothing more than rapturous utopia, they were nevertheless part of a creative new spirit: everything can be explained, nothing is unattainable. Numerous literary works that are still known today, such as Mary Wollstonecraft Schelley's "Frankenstein" (or the modern Prometheus, 1818) or Jules Verne's "Die Reise zum Mittelpunkt der Erde" (1864) were created and fascinated generations.

${ }^{13}$ We would like to recall the following popular ideas, which have lastingly changed the image of mankind. Not every scripture still stands up to scientific scrutiny today. Some even had terrible consequences. This incomplete list is therefore about influence, not scientific value:

- Theory of evolution (Charles Darwin, 1859)

- Psychoanalysis (Sigmund Freud, since 1883)

- Anthropogeny (Ernst Haeckel, 1874)

- Theory of inheritance (Georg Mendel, from 1856)

- Inequality of human races (from Joseph Arthur de Gobineau 1853)

- Mass Psychology (Gustave Le Bon, 1895)

- Popularization of Racism (Houston Stewart Chamberlain, from 1899)

- Popularization of Communism (Karl Marx, from 1849)

${ }^{14}$ A milestone here is certainly Gustave Le Bons' "Psychology of the Masses" of 1895. Le Bons is regarded as the founder of mass psychology. Even deeply influenced by Charles Darwin and Ernst Haeckel, he radiated not only on Siegmund Freud, who in his 1921 work "Massenpsychologie und Ich Analyse" (Mass Psychology and I Analysis) 


\section{International Journal of Social Science and Economic Research}

ISSN: $2455-8834$

Volume: 05, Issue: 01 "January 2020"

- Business (sales, brand development, brand management, advertising, etc.) ${ }^{18}$

- Politics (political propaganda, advertising, communication and other areas)

- Technology (types of communication themselves and their means) ${ }^{19}$

These areas merge and interact with each other. Not until you're in the alcove. Later, politics and business acted as merging elements ${ }^{20}$ and provided for the practical implementation of some theory and thus also for the emission of stimuli. ${ }^{21}$ While these two power factors were still competing until the Second World War, capitalism attained the primacy of practice at the latest after the end of the cruel slaughter, begins to dominate the interactions and orients them towards itself. At least in the western world, while in the socialist zone of influence the stimulus and practical use of the insights was further shaped by the political level. However, this eastern development is of less interest to us. Instead, we look at the Western world after the end of the Second World War. The following phases, which are shaped by the economic system, can be identified here: ${ }^{22}$

refers directly to the Frenchman, but also to Hitler and Stalin. Especially the passages on propaganda in Hitler's "Mein Kampf" show astonishing parallels to Le Bon's work.

${ }^{15}$ Although there are also precursors, this is usually attributed to Sigmund Freud. Since then, this sector has been expanded many times and knows numerous individual disciplines.

${ }^{16}$ This begins with Darwin and continues through to brain research.

${ }^{17}$ In the sense that it must regulate the relationships between people and their behaviour by law. Questions such as legal capacity, will, maturity or accountability are of decisive relevance here.

${ }^{18}$ The word "sale" may sound profane, but as long as there is no total seller's market paired with a monopoly or at least an oligopoly, it is important to sell the goods in question. This again required corresponding considerations, which were refined further and further.

${ }^{19}$ The stimulus must always also find its way to the recipients. The technical progress made it possible to widen and extend this ever further.

${ }^{20}$ Critics may argue here that this bipolar representation could, for example, be supplemented by the free press, but on the one hand we don't want to get lost in too many details and on the other hand it can be argued that with a primacy of politics the press was usually also brought under control, while with a primacy of the economy it can also be regarded as a market participant. In fact, this clear demarcation does not exist either and serves only for simplification-

${ }^{21}$ While in the USA, for example, the capitalist economic system very quickly assumed a dominant role in the emission of stimuli, in Europe and the rest of the world the state often played a more important role. Of course, the fascist and communist blocs were extreme here.

${ }^{22}$ It should be noted that these times may vary slightly for individual countries in the West. 


\section{International Journal of Social Science and Economic Research}

ISSN: $2455-8834$

Volume: 05, Issue: 01 "January 2020"

- From 1950: Orientation of economic marketing towards production due to post-war demand. This is - after the war - so large that the products practically sell themselves. Large applications are not necessary at all.

In the political arena, too, the population is grateful for an appropriate offer of political content and accepts it. Particularly in countries such as West Germany, experience with National Socialist propaganda has shown that restraint is practically a state reason. The ${ }^{23}$ stimulus influence is still strong, limited to a few media and the public ${ }^{24}$. Withdrawal is easy and the stimuli are even directly related to increasing wealth and mass consumption. ${ }^{25}$

- From 1960: Orientation towards sales methods and distribution. The demand is still gigantic, but it will be necessary to remind the customer. Scientific findings on influencing are gaining in importance. ${ }^{26}$

The same applies to political marketing. A large part of society is still satisfied with the supply, but the first demand for political goods begins to emerge in the middle and at the end of the decade, which can no longer be satisfied by the current supply. The first political movements beyond the established spectrum are perceived by a broad public. ${ }^{27}$

${ }^{23}$ In addition, with the onset of the Cold War, a clear external enemy image emerged that could be used profitably for political messages.

${ }^{24}$ Here we are talking specifically about media such as newspapers, advertising journals, advertising at the point of sale or the surrounding area or radio. Although television started in many Western countries, apart from entertaining experiments in the $30 \mathrm{~s}$, as a rule already in the $50 \mathrm{~s}$, it only reached a fraction of consumers.

25 There was even the popular thesis that mass consumption would eliminate the social hierarchies of society. Capitalist socialism, so to speak.

${ }^{26}$ The basics of marketing are of course much older, because they are as old as selling itself is. Looking only at the end of the 19th century and the beginning of the 20th century, Gustave Le Bon's "Psychology of the Masses" of 1895 also contains very concrete considerations in this area;

"[...] So one of the most important tasks of statesmen is to baptize the things that the masses hate under their old names with popular or at least meaningless names. The power of words is so great that well-chosen terms are enough to make the most hated things acceptable to the masses. [.. "

The foundations were therefore already in place. Now it was more a matter of concrete implementation and theories such as behaviorism provided new approaches.

${ }^{27}$ In the 1960s, a generation conflict develops, which finds its discharge among other things in the protests against the Vietnam War or in anti-capitalist movements. Political impulses and alternatives thus emerged outside the establishment. These were loud at first, but were still supposed to unfold their effect. These new milieus have not been dealt with for a long time. 


\section{International Journal of Social Science and Economic Research}

ISSN: $2455-8834$

Volume: 05, Issue: 01 "January 2020"

The methods of transmitting stimuli are becoming more widespread as television becomes more widespread. They are not yet perceived as unpleasant. On the contrary, many Western countries are still very satisfied with the prosperity and consumption they have achieved. ${ }^{28}$

- From 1970: Orientation on the market. Demand is saturated and producers are forced to research consumer needs more closely and make targeted offers. This also includes a deeper and experimental investigation of the often theoretical knowledge about human behaviour, some of which was already established in the 19th century (e.g. behavioural research, brain research, etc.). At the same time, criticism of mass consumption is finally emerging from the niche.

First of all, the political market is following the changed market situation: the established political forces are adapting successfully to some extent and, where this does not succeed, more and more extra-parliamentary opposition movements are establishing themselves as new providers. It is now obvious that they will exert lasting political influence. Your march through and into the institutions is imminent.

Concrete stimulation is now needed in order to be able to sell products, be they economic or political. Despite the growing criticism of the stimulus setting, the established media are a good means of doing this, as they clearly dominate the market for the stimuli. ${ }^{29}$

- From 1980: Orientation towards competition. The market is highly competitive and market shares are won by those who can present unique selling propositions. Image and brand management are becoming increasingly important. At the same time, the brain's mechanisms of perception are being researched even more intensively and are being used in the application process. ${ }^{30}$

Similarly, more and more political players are emerging who can unite market shares (= votes). The established political forces are trying to incorporate the unsaturated demand for political goods (e.g. environmental protection) into their existing brand core, but this is only partially successful. Political marketing is becoming more and more oriented towards economic marketing.

\footnotetext{
${ }^{28}$ However, the thesis of social unification through mass consumption is abandoned and more or less the opposite is now postulated: by 1965 at the latest, this approach will also be viewed critically.

${ }^{29}$ Criticism is a stylistic device of time. Separating politics and business here would be meaningless, because it was a comprehensive questioning of the Western system.

${ }^{30}$ These include elements such as the "eye camera", which tracks exactly what goods a customer sees in a supermarket, how and for how long, and from which it is in turn concluded how the consumer goods could be placed on the shelves at the sales-promoting location.
} 


\section{International Journal of Social Science and Economic Research}

ISSN: $2455-8834$

Volume: 05, Issue: 01 "January 2020"

Advertising stimuli are now ubiquitous and part of the consumer society. The criticism is now socially acceptable, but the suggestions are still accepted. ${ }^{31}$

- From 1990: Orientation towards the milieus. Society has changed in recent decades. Customers have to be addressed individually in their reality of life. Only very few products still function on their own, and the competition is fierce. The presumed findings from behavioural and brain research are now regarded as indispensable. The milieus that have emerged allow consumer criticism and unbridled mass consumption to coexist comfortably. ${ }^{32}$

At the same time, politics is increasingly orienting itself towards milieu models in order to reach people. Here, too, competition has increased. There is a growing conviction that image and brand management are more important than the product itself, in this case the political content. The application of manipulation techniques via speech and images reaches a $\operatorname{climax}^{33}$

Politics, media and business are now exhausting the possibilities of transmitting stimuli through existing means of communication and reaching a maximum level of perfection. But the mobile phone and the Internet promise an end to this dominance, although these new possibilities still play a subordinate role.

Terms such as "sensory overload" have already penetrated everyday language, but the last two generations have already grown up with it and therefore, despite the increase in the intensity of the stimuli, often see no need for withdrawal. ${ }^{34}$

- Since 2000: Expansion of the constantly developing milieu view through new media and technologies. The digital world expands the possibilities to reach customers massively and opens new perspectives on all levels. In addition, completely new markets and business fields are emerging, which are slowly shaking the current economic and political power

\footnotetext{
31 The social situation had calmed down, while in parallel the political alternative to the West, the communist system, had become massively less attractive and it became increasingly apparent that it was about to collapse. In addition, a new generation grew up who had already been born into a consumer society. The milieus changed and split.

${ }^{32}$ The side of mass consumption is clearly the bigger one. Self-realization is becoming more and more important.

${ }^{33}$ Today one would call these techniques e.g. framing or priming.

${ }^{34}$ For the 90s, the term "fun society" is often used to describe them globally for Western countries. This blanket term is of course not correct, although it also points to massive social changes by highlighting the hedonistic milieu that has emerged.
} 


\section{International Journal of Social Science and Economic Research}

ISSN: $2455-8834$

Volume: 05, Issue: 01 "January 2020"

relations ${ }^{35}$ Behaviour is increasingly becoming a production factor and behavioral capitalism is beginning to establish itself as a new variety of capitalism. ${ }^{36}$

The world is spinning faster and the fragmentation of milieus caused by the change of times releases a hardly foreseeable dynamic. The safe is called into question. A circumstance that sows the seeds of alienation that is to rise in the following decade.

In contrast to the economy, the political world reacts with considerable delay to ${ }^{37}$ technological change and the change of times and prefers to rely too long on individual, ageing milieus that remain loyal to a particular political party, often regardless of the content.

In addition, one is under the illusion that the strong influence on those forces that the majority of the population has used as information media (e.g. newspapers, television) will continue to dominate communication in the future. That a controllable small narrow point, which all ships have to pass, slowly turned into a broad river, which becomes an ocean, they do not recognize or much too late. The digital world remains alien and incomprehensible for so long, even though mobile phones and the Internet are clearly gaining ground and modern smartphones will gain massive market shares in the mobile sector by 2007 at the latest.

The sensory overload has meanwhile turned into a sensory bombardment. But since generations are used to it, this increase, outside certain milieus, hardly plays a relevant role in media criticism any more. In addition, possibilities of dialogical stimulation are also established. It is less and less a case of one-sided communication, but rather the active demand for stimuli plays a central role in the new stimulus society.

- From 2010: The markets have changed completely. The customer now has extensive possibilities for information. Internet use and the smartphone are part of everyday life. ${ }^{38}$ The market is now truly transparent, which requires completely new strategies.

\footnotetext{
${ }^{35}$ For example, the current technology giants Google (1998), Ebay (1995) and Amazon (1994), founded in the 90s, experienced their breakthroughs in this period, while others such as Facebook (2004) or Youtube (2005) were only just founded.

${ }^{36}$ First Foundations of Behavioral Capitalism: A New Variety of Capitalism Gains Power and Influence, Andreas Herteux, Erich von Werner Verlag, 2019, ISBN 978-3981900675, DOI 10.5281/zenodo.3469568

${ }^{37}$ This term is already euphemistic, because in reality large parts of the political establishment do not react at all and do not understand the change of times.

${ }^{38}$ All it takes is a simple ride on a tram in a big city and the observation that a large number of people on the move will be permanently occupied with the smartphone and the knowledge that entire generations have been or will be shaped in this way.

Of course, this can also be backed up with figures, because in Germany in 1999 there were still less than 25 million mobile phone contracts, in 2018 there were slightly less than 130 million. An impressive number with a clearly discernible tendency:
} 


\section{International Journal of Social Science and Economic Research}

ISSN: $2455-8834$

Volume: 05, Issue: 01 "January 2020"

The siphoning off of individual data and the recognition of individual customers' needs becomes the focus of attention. To maximize this, the customer is maximally embedded and appropriate information is siphoned off. Not all customers and realities can be reached with this method, but the proportion is growing steadily. The ${ }^{39}$ principle of the stimulus dialogue, according to which stimuli are also requested by earlier recipients (= customers, voters, interested parties, consumers, etc.), changes communication sustainably.

Behavioural capitalism is firmly established and is gaining more and more power and influence. ${ }^{40}$

The established political forces are still predominantly guided by outdated milieu models. She no longer or only marginally perceives the intensified milieu struggle and the further erosion of the realities of life. While politics had once approached and adopted economic advertising methods, it is now showing too little willingness to deal with the new possibilities.

Proven stimuli and forms of communication lose their effectiveness. The digital world has been underestimated as a source of information, just as the impact of previously successful media (e.g. television) is still overestimated.

One is not sufficiently prepared for the new kinds of communication, as well as for the change of times in general, and thus makes strategic wrong decisions, which lead to an alienation and a wrong assessment of the needs of the voters. The result is the massive loss of market share (=voters' votes) and the opportunity for new political forces, which do not necessarily have to appear in the form of political parties, to win them over quickly.

The constant presence of stimuli is already normal for large parts of the milieus and is not perceived as unpleasant. On the contrary, people like to voluntarily expose themselves to them as long as they satisfy their own needs. In many cases, the stimuli are even expressly desired and their absence is considered a deficiency. ${ }^{41}$

It is not intended at all to evade these stimuli, but on the contrary, they are intended and, in the form of the device, always carried with you. Perhaps there is already a certain degree of dependence.

${ }^{39}$ Ultimately, it is only a biological question until every living generation will have grown up in a world full of charms.

${ }^{40}$ First Foundations of Behavioural Capitalism: Inventory of a New Variety of Capitalism, by Andreas Herteux, published by Erich von Werner Verlag, 2019, ISBN 978-3981900651, DOI 10.5281/zenodo.3469587

41 Internet addiction is now also recognized as a disease (classification according to ICD-11). The smartphone dependency could follow this soon. Of course, not everyone who waits longingly for the next message or checks his likes or status can be described as sick. We're talking extremes here. 


\section{International Journal of Social Science and Economic Research}

ISSN: $2455-8834$

Volume: 05, Issue: 01 "January 2020"

The combination of behavioral capitalism and stimulus society ushers in a new era: Collective individualism.

- The age of collective individualism: Attempting to embed the customer completely and to experience his needs directly and to fulfil them as promptly as possible. For this purpose, a permanent data collection through digital networking is indispensable. Individual control via algorithms and bots in the own digital reality of life with simultaneous fusion of the digital and the real world. Consumption becomes more individual and yet it is only an illusion, since the methods are controlled collectively. The complete establishment of collective individualism, however, still fails because of the milieu struggles. It must therefore be regarded as incomplete. The life in an own world, however, will be possible in large parts.

The political establishment continues to lose market share and will partially disappear into insignificance if no radical turnaround succeeds. Individual parties and new movements are connecting to modernity, but do not have the same data and embedding mechanisms as the established corporations. New forms of political marketing will therefore be established.

However, the groups have the corresponding behavioural data and the question of whether these companies will therefore not have a far greater influence on the existing order in the future than they already have must certainly be asked. $\operatorname{In}^{42}$ general, however, there is a tendency for the primacy of the economy to prevail in the western world, while in the controlled capitalism of eastern character, politics shows the will to dominate behavioral capitalism. Just think of China's social credit system. That both worlds will meet brutally and inevitably is mentioned, but not relevant for this scripture.

Technology continues to advance, improving communication methods and embedding possibilities. The stimuli now occur permanently in both directions. The original sender (seller, political force, medium, etc.), whose role is likely to be taken over completely by an $\mathrm{AI}$ at some point, stimulates the original recipient (customer, voter, interested party, etc.) and the homo stimulus in turn constantly sends impulses of need, without this procedure being questioned by the general public. The result is a dialogue that finally replaces old marketing methods. Since the exchange of stimuli serves one's own desire, they are perceived as positive. Ultimately, they serve the purpose of researching and serving needs and lead to an individualized reality in which everything revolves around the homo stimulus and which was created solely for it. ${ }^{43}$ Last criticism comes with the aging and disappearance of older generations out of fashion.

\footnotetext{
42 This, of course, is a possible future, whether it will come to that is yet to be seen. The tendency is present.

${ }^{43}$ Since the world is individual, but it is formed according to the same rules for all, it should be remembered that we call this age, that of collective individualism.
} 


\section{International Journal of Social Science and Economic Research}

ISSN: $2455-8834$

Volume: 05, Issue: 01 "January 2020"

The form of impulse transmission could also develop further, because if the effect of stimuli has been described so far, the impression arose that they inevitably have an external effect. This will also predominantly shape the near future for a large part of the population.

The probability that the homo stimulus will soon be exposed not only to external but also to internal stimuli is given. This means nothing less than that the inside of the body is directly influenced, whereby it should be pointed out that the term "stimulus" must now be interpreted as broadly as possible.

The idea that controlling stimuli are triggered directly in the body, preferably in the brain, is an unpopular, but nevertheless realistic one. Here it would be just as conceivable to mix humans with machines as it would be to set chemical or genetic impulses. The technological change brought about by the change of times will permit interventions in a few years' time that still seem absurd today, but are in part already on the verge of a breakthrough. The targeted stimulation of the brain is also no longer unknown. Just think of the current findings in active prostheses, for example, in which implants under the skin trigger a coordinated electrical stimulation, i.e. a stimulus, which in turn sends the corresponding impulses to the corresponding nerve cells in the brain and thus gives the affected person more mobility again. Experiments in which electrical stimuli work on the area of the brain responsible for anxiety and nervousness have been so successful that the treatment of severe depression with the help of implanted electrodes has now been used successfully for more than 10 years to combat the most severe mental disorders. ${ }^{44}$ Deep brain stimulation could become a fashion trend. The development from repair and life extension to optimization will certainly be one.

Whether through chemistry, implants, physical networking or anything else - human optimization has only just begun. Some milieus will benefit more quickly, some later and others probably never. But this aspect of the change of times cannot be stopped. The internal appeal is thus already reality, and when we think about it more closely, it has always been so. Think only of medications for depression or drugs. What is this less than a biochemical intervention that ultimately has a change of character and behaviour? The ${ }^{45}$ difference lies, as

\footnotetext{
44 Although the number of 200 patients worldwide so far does not sound impressive, a start has been made. The risks, which, forgive the profane language, are a hole in the head, are on the other hand manageable, the promise against it, not only to fight diseases in the long run, but also to increase performance, on the other hand enormous.

${ }^{45}$ But this should only be an excursus and in the end there are only two things to take with you:
}

- That the technological aspect of the change of times will not only intensify external but also internal impulses. However, the question of exactly which will prevail must still remain open today. However, the classic external stimuli will continue to play a more dominant role. 
already emphasized, however, hidden in the fact that now no weaknesses will be compensated, but the human being will be optimized more than ever.

\section{Implementation of the stimulus society}

So much for our brief foray into the history and possible future of the stimulus society, which is ultimately always part of the collective individualism itself. The fact that the brevity of the presentation always requires a concentration of information is part of the nature of the matter.

In the end it was about the thesis of the stimulus society and the homo stimuli and only about these. In sum, it can be said that the number and intensity of stimuli have increased massively since the end of the Second World War and that stimulation is now practically indispensable for entire environments. The stimulus society is therefore a reality. The same applies to behavioural capitalism, which cannot be separated from it. For the homo Stimuli, the intensified stimuli are considered an indispensable part of individual life. He's even calling them in. Man has been conditioned and trained. Usually, to process a variety of short, fast stimuli within a short time span. This adaptation, however, is not part of a purposeful conspiracy, ${ }^{46}$ but rather in the course of a development in which manifold forces and their interactions met first and were later dynamised by the change of times.

- And hopefully, dear reader, you will also take with you a certain curiosity about these new technologies. There is a lot of information. It is often already possible today to do far more than even the wildest dreams would suggest

${ }^{46}$ Such "re-education theses" are repeatedly put forward in the observation of such a historical course of events. The belief that a single force or even a single person can exert such an influence permanently is absurd. Rather, all human beings are subject to this process. Some profit, others don't. It cannot be prevented. 


\section{Embedding process}

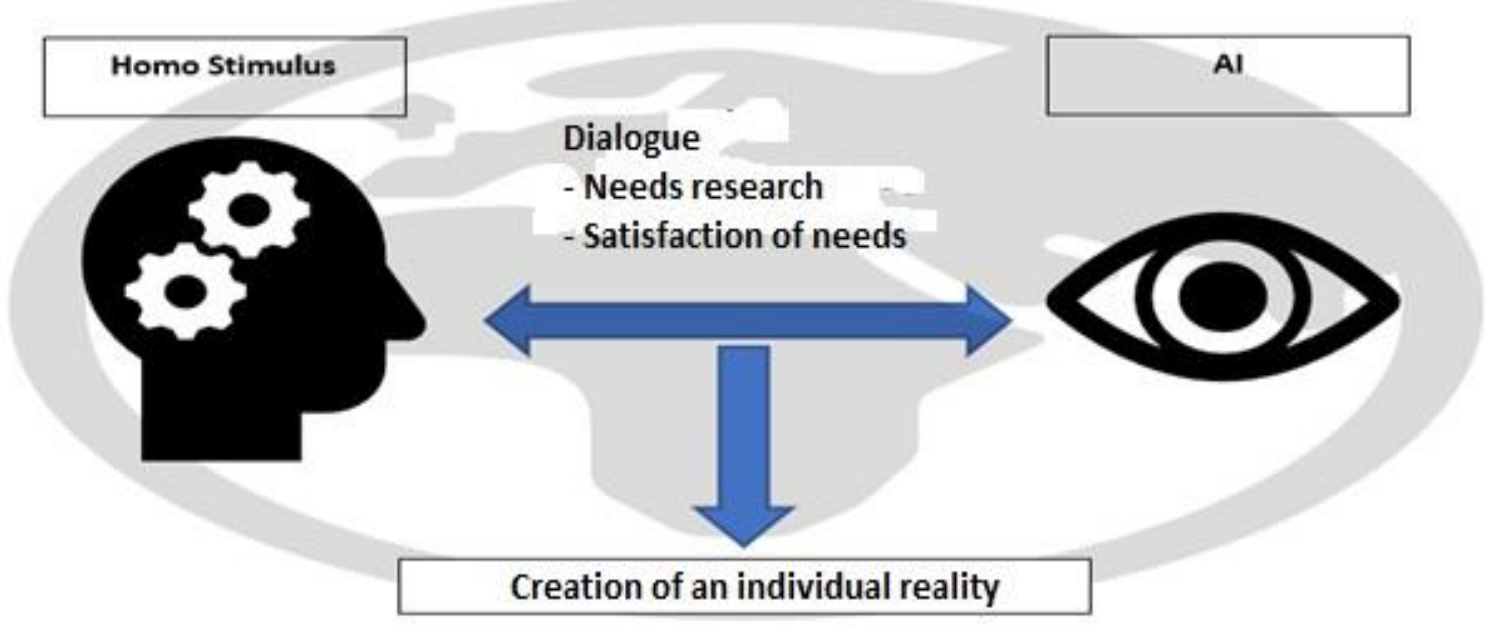

Alle Rechte Erich von Werner Gesellschaft 2019

The resulting homo stimulus will not only be accustomed to the stimuli, but will also demand them and is willing to react with its own stimuli and thus enable embedding communications and actions.

He enters into a dialogue with the goal of his own needs research and fulfillment. This dialogue allows him a maximum level of personal self-realization and the creation of his own reality, which has him in the center.

The question of future discussions will therefore not be how to prevent the homo stimulus. No, he is already reality and with each new generation his share will grow. No, the discussion must revolve around how life should be shaped in the age of collective individualism and what degree of self-determination must be maintained. It's about a lot, if not everything.

\section{REFERENCES}

(Studies are not listed separately, but are linked in the text. Mentions or references to standard works in the historical context are also treated with a reference to them).

- "The Psychology of the Masses", Gustave Le Bon, Nikol Verlags-GmbH, 2008, EAN EAN:9783868200263 
International Journal of Social Science and Economic Research

ISSN: $2455-8834$

Volume: 05, Issue: 01 "January 2020"

- „Die Psychologie der Massen“, Gustave Le Bon, Nikol Verlags-GmbH, 2008, EAN EAN:9783868200263

- "First Foundations of Behavioral Capitalism: A New Variety of Capitalism Gains Power and Influence", Andreas Herteux, Erich von Werner Verlag, 2019, ISBN 9783981900675, DOI 10.5281/zenodo.3469568

○ "Erste Grundlagen des Verhaltenskapitalismus: Bestandsaufnahme einer neuen Spielart des Kapitalismus", von Andreas Herteux, erschienen im Erich von Werner Verlag, 2019, ISBN 978-3981900651, DOI 10.5281/zenodo.3469587.

○ "Premiers fondements du capitalisme comportemental: Un inventaire d'une nouvelle variété de capitalisme", Andreas Herteux, Erich von Werner Verlag, 2019, ISBN 9783981900682, DOI 10.5281/zenodo.3517802

- "Le prime basi del capitalismo comportamentale: Inventario di una nuova varietà di capitalismo", Andreas Herteux, Erich von Werner Verlag, 2019, ISBN 9783948621025, DOI 10.5281/zenodo.3517835

○ "Primeiras Fundações do Capitalismo Comportamental: Um inventário de uma nova varied-ade de capitalismo", Andreas Herteux, Erich von Werner Verlag, 2019, ISBN 9783948621018, DOI 10.5281/zenodo.3517837

- "Primeros fundamentos del capitalismo conductual - Un inventario de una nueva variedad de capitalismo," Andreas Herteux, Erich von Werner Verlag, 2019, ISBN 9783948621001, DOI 10.5281/zenodo.3517839

○ "Первые основы поведенческого капитализма: Инвентаризация нового разнообразия капитализма", Andreas Herteux, 10.5281/zenodo.3517841

- De eerste stichtingen van het gedragskapitalisme - Een inventaris van een nieuwe variëteit van het kapitalisme, Andreas Herteux, Erich von Werner Verlag, 2019, ISBN 978-3-948621-03-2, DOI 10.5281/zenodo.3521230

- Pierwsze fundamenty kapitalizmu behawioralnego - Inwentaryzacja nowej odmiany kapitalizmu, Andreas Herteux, Erich von Werner Verlag, 2019, ISBN "978-3-948621-05-6 DOI 10.5281/zenodo.3521294

- „The Alternative Hegemony Model (AH Model): The "invisible hand" of nurture for the better", Andreas Herteux, Erich von Werner Verlag, 2019, ISBN 978-3-9819006-1-3, DOI 10.5281/zenodo.1894461 
International Journal of Social Science and Economic Research

ISSN: 2455-8834

Volume: 05, Issue: 01 "January 2020"

○ „Das Alternative Hegemonie Modell (AH-Modell): Die unsichtbare Hand der Erziehung zum Guten“, Andreas Herteux, Erich von Werner Verlag, 2019, ISBN 978-3-9819006-4-4, DOI: 10.5281/zenodo.1894403

- „Grundlagen der Weltenphilosohpie, Andreas Herteux,“ Erich von Werner Verlag, 2015, ISBN 978-3945509029

- „Identitätsorientierte Führung einer politischen Marke: In der Theorie und am praktischen Beispiel der Freien Demokratischen Partei (FDP)“, Andreas Herteux, Erich von Werner Verlag, 2013, ISBN 978-3639490480 